\title{
Article
}

\section{Who walks, where and why? Practitioners' observations and perspectives on recreational walkers at UK tourist destinations}

Davies, Nicholas James

Available at http://clok.uclan.ac.uk/19316/

Davies, Nicholas James ORCID: 0000-0002-9889-1205 (2018) Who walks, where and why? Practitioners' observations and perspectives on recreational walkers at UK tourist destinations. Annals of Leisure Research, 21 (5). pp. 553-574. ISSN 1174-5398

It is advisable to refer to the publisher's version if you intend to cite from the work. http://dx.doi.org/10.1080/11745398.2016.1250648

For more information about UCLan's research in this area go to http://www.uclan.ac.uk/researchgroups/ and search for <name of research Group>.

For information about Research generally at UCLan please go to http://www.uclan.ac.uk/research/

All outputs in CLoK are protected by Intellectual Property Rights law, including Copyright law. Copyright, IPR and Moral Rights for the works on this site are retained by the individual authors and/or other copyright owners. Terms and conditions for use of this material are defined in the policies page. 


\title{
Who walks, where and why? Practitioners' observations and perspectives on recreational walkers at UK tourist destinations
}

\author{
Davies, NJ \\ http://dx.doi.org/10.1080/11745398.2016.1250648
}

\begin{tabular}{|l|l|}
\hline Title & $\begin{array}{l}\text { Who walks, where and why? Practitioners' observations and perspectives } \\
\text { on recreational walkers at UK tourist destinations } \\
\text { Authors }\end{array}$ \\
\hline Type & Article \\
\hline URL & \\
\hline Published Date & 2016 \\
\hline
\end{tabular}




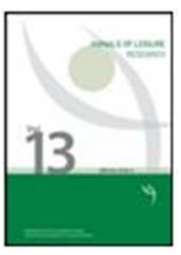

\section{Who walks, where and why? Practitioners' observations and perspectives on recreational walkers at UK tourist destinations}

\begin{tabular}{|r|l|}
\hline Journal: & Annals of Leisure Research \\
\hline Manuscript ID & RANZ-2016-0009.R2 \\
\hline Manuscript Type: & Original Article \\
\hline Keywords: & $\begin{array}{l}\text { Walking, Recreation, Outdoor adventure tourism, Visitor management, } \\
\text { Walking tourism, Confidence }\end{array}$ \\
\hline \multicolumn{2}{|c}{} \\
\hline
\end{tabular}

\section{SCHOLARONE}

Manuscripts 
Title:

\title{
Who walks, where and why? Practitioners' observations and perspectives on recreational walkers at UK tourist destinations
}

\begin{abstract}
:
Walking is fundamental and prevalent in all tourist settings. It is the most popular activity in natural spaces and managed outdoor recreation areas, yet receives less attention in academic literature than it should. This paper conceptualises recreational walking, using the findings of a UK-based exploratory study. Twenty three in-depth interviews were undertaken with expert practitioners involved in the management of the walking world. The discourse revealed insights into characteristics and motivations for recreational walking. A diverse range of individuals participate, who demonstrate differing levels of commitment to walking, from short walks for sightseeing purposes to more challenging physical experiences on a more frequent and committed basis. Individual confidence is particularly important in determining how people choose to undertake walks, their level of involvement in the activity, and how they navigate themselves. The interview findings suggest that walkers can be casual or serious in their interest in walking. These distinctions are useful in separating walking in terms of adventure tourism and other forms of tourism.
\end{abstract}




\section{Who walks, where and why? Practitioners' observations and perspective on recreational walkers at UK tourist destinations}

\section{Introduction}

Walking is a universal tourist activity, encompassing the full spectrum of recreational participation; from intensive long-distance trail-walks and dedicated walking holidays to short unplanned walks at destinations by tourists on a more general holiday. Motivations to walk are diverse, and include experiencing the social and cultural dimensions of places; health, physical rehabilitation and mental wellbeing; adventure; the discovery and interpretation of heritage; access to locations for wildlife and nature-based tourism; pilgrimage and spirituality (Moscardo, 1996; Murray and Graham, 1997; Reynolds and Braithwaite, 2001; Lumsdon and Spence, 2002; Beedie and Hudson, 2003; Connell, 2006; Sharpley and Jepson, 2011).

Whilst there is a presence in academic literature of recreational walking at tourist destinations more generally, analyses of the walking experience and decision-making process do not portray the diversity of those who walk, nor the walks they choose. Walking has been included in the context of literature on the recreation and park movement, emergent from the late $19^{\text {th }}$ century, principally from North America and Western Europe. Exploration of both recreation and tourism often jointly analyses a number of recreational activities in outdoor spaces in terms of their impact management, user profiles, user preferences for activities or environments, risk management, conflicts, motivations or experience (Jacob and Schreyer, 1980; Manning et al., 2000; Torkildsen, 2005; Pigram and Jenkins, 2006; McLean et al., 2008; Dickson and Gray, 2011), but often misses the nuances involved in walking as a focal activity.

Walking is fundamental in adventure tourism destinations, where roads, cars and infrastructure are often scarce. Accessing sites for more strenuous activities such as climbing, rivers for water based activities, or other remote areas for recreation will often necessitate some walking. For a considerable proportion, walking itself is the main or most strenuous activity. When considered more broadly, the range of different walks spans the adventure tourism niche, in addition to more general forms of tourism. For instance, long mountain walks are invariably undertaken by a different subset of tourists than much shorter 'strolls' in rural destinations. Stakeholders providing resources for recreational walking branch many sectors; ranging from tourism organisations to equipment retailers, environmental organisations and health authorities. If one considers the breadth of participation and 'types' of walking, it is arguably the most all-encompassing recreation activity, which leads on to the purpose of this paper.

It is particularly important for those involved in the supply and management of walking resources to know more about its participants. Research can fulfil fundamental purposes in adding to the body of knowledge in a number of areas, and more specifically adventure tourism: as a vital form of travel for activities and around destinations; a frequent tourism 
activity in itself; a form of active travel; and a means for tourism managers to incorporate more sustainable approaches into visitor management. Additionally, with the increase of slow tourism, slow adventure and most pertinently slow travel, walking offers a suitable mode to experience places at a slow pace. This paper conceptualises recreational walking, using the findings of a qualitative UK-based exploratory study from the supply perspective. It seeks to investigate the practitioner view on the behaviour of walkers; using the observations of countryside recreation managers and a range of organisational representatives from a nebulous recreational supply sector. Ultimately it produces insight on the preferences and motivations of walkers for locations; and appraises some underlying grouping characteristics of walkers, to understand more clearly the diversity in evidence.

\section{Literature review}

\subsection{Walking studies in the fields of tourism, adventure tourism and outdoor recreation}

Published articles which directly analyse walking in tourist spaces will generally seek to understand an aspect of tourism, using walking as a focal point. Examples include: a study on the Inca Trail, which explores the route as the actual tourist experience (rather than the destination) (Cutler et al. 2014); and investigation into meanings and interpretations of historical culture for stakeholders associated with a heritage walking trail in Hong Kong (Cheung, 1999). Other studies look at motivation, behaviour and route-choice (McNamara and Prideaux, 2011). The movement of tourists, particularly in sensitive areas, is an important research goal, and many movements recorded are walking routes. For instance, Orellana et al. (2012) modelled visitor movement patterns in natural recreation areas, identifying most-visited locations in the park, and the most frequently used routes. This study and others like it (see Davies, 2012) inform the development of resources, promotion, management and monitoring of recreational walking sites, highlighting the diversity of walkers' needs including transport, information, and the dichotomy between preferring natural spaces with no signage, and tourists requiring information and interpretation.

Whilst tourism is a relatively new 'field' of study, whose discipline status is still being debated (Tribe, 1997), adventure tourism study is still framing itself. In 1987, Ewert published an overview of previous research, providing a definition for outdoor adventure recreation: 'a self-initiated, non-consumptive recreational activity engaged in a natural outdoor setting, that contains real or perceived elements of risk in which the outcome is uncertain but influenced by the participant and/or circumstance' (Ewert, 1987). The inclusion of 'risk' in this definition indicates a restriction towards more 'adventurous' forms of walking tourism. More recently, Weber (2005) noted the tendency of adventure-based recreation studies to neglect the tourism element. Beedie and Hudson (2003) state that mountaineering as a specialist activity now overlaps more with tourism. They suggest that hillwalking in exotic places has been 'redefined as trekking' and that the increase in classifications is a result of the broadening of activities over time. The authors describe three key areas in defining adventure tourism: control is deferred to experts, promotional media is used frequently and technology is used in adventurous settings. It is clear therefore, that the 
development of understanding in this area reflects a degree of flux in two elements: categorisation of activities; and the criteria used to classify them as adventure tourism.

The terms used for 'types' of walking in academic literature include specialist activities such as hiking, back-packing and mountaineering. It can be difficult to differentiate; the terms walking and hiking are often used interchangeably (an example being Lieber \& Fesenmaier, 1984). Ewert (2000) uses activity-based terms including hiking, hiking to a summit, backpacking, backpacking to a summit, mountain climbing and rock climbing (raising a further consideration regarding the boundary between walking and climbing). In adventure recreation spaces, activities may be hard or soft, based on levels of regulation and independence, risk and control (Ewert, 2000). Organised walking groups can be highly regulated and structured, for example (Davies and Weston, 2015). Recreation and tourism activities often occur in the same physical spaces; for example National Parks (McKercher, 1996), the countryside, and urban green spaces; and overlap other areas including ecotourism and activity tourism (Pomfret and Bramwell, 2014). Based on Ewert's definitions, spaces vary widely from highly controlled walking activity with low risk certainty and more available amenities (such as manicured forest parks with car-parking, toilets and short easy trail walks) to higher risk, lower control and less amenities (hillwalking or mountaineering). Categorisation of people, activities and places allows academics and managers to understand walking tourists' motivations for different experiences and preferences for walking locations.

\subsection{Segmenting walkers and understanding diverse walking preferences}

Differentiating between walkers, either by characteristics or walking behaviour is seldom focused upon in tourism or any other branch of study. A typology was developed for urban pedestrians based on their route preferences (Millonig and Gartner, 2009), but this falls short of analysis of tourism behaviour. Kay and Moxham (1996) attempted to classify walkers to explore the notion of 'hoardes' clogging up the countryside. The study utilised a classification of twenty types of walking (rather than the walkers themselves they focused on the activity), ranging from occasional short strolls to 'Munro-baggers' (and including sauntering, ambling, strolling, tramping, rambling, hill-walking, and yomping). They were generated subjectively based on five dimensions: difficulty of the walk, ability of the participants, level of planning required, where the walk was on a scale ranging from 'relaxing and sociable', to 'challenging and rewarding', and where the walk fits on a continuum between mainstream activity and esoteric minority activity. The exercise highlighted the diversity of walking as an activity. Other instances where researchers have attempted to categorise walkers include: research subjects self-classifying themselves as hillwalkers under the umbrella of mountaineering (Highlands and Islands Enterprise, 1996), and studies of visitors to natural areas which focus on multiple forms of outdoor recreation, in which walking and hiking are differentiated from other activities (Tomkins, 1990, Brandenburg and Ploner, 2002). The diversity of walk types, the true nature of walkers and their route-choices is not illustrated in these categories. The relationship between walker and location is much more complex than often considered to be in the literature (Den Breejen, 2007). 
The process of segmentation in tourism allows links to be drawn between activities in outdoor recreation and characteristics such as age and gender (Pomfret and Bramwell, 2014). Segmenting tourists on their characteristics, travel activities and patterns can produce tangible 'groups' for which marketing can be targeted (Bryant and Morrison, 1980). In rural tourist areas, 'psychographic' segmentation based on more unique characteristics including lifestyle, personality, recreational expectations and motivations can explain visitor behaviour (Frochot, 2005; Molera and Albaladejo, 2007). Exploration of motivations is not new in tourism study, and has developed from understanding the 'needs' one feels to offset everyday normality and stress with more fulfilling, relaxing and exciting activities (Dann, 1977; Crompton, 1979; IsoAhola; 1982). These needs are universal to walking and other forms of recreation. Other needs reflect benefits of recreation such as health and well-being (Wolf and Wohlfart, 2014), social interaction and nature (Lepp and Herpy, 2015).

Hill et al. (2008) examined the Appalachian Trail finding that hikers' benefits were associated with the wilderness experience, as visitors achieved greater self-fulfilment and self-esteem, as a consequence of sharing the activity experienced camaraderie, and companionship. The affective benefits of walking also include relaxation, no stress, control, excitement and freedom (Anable and Gatersleben, 2007). In any travel-related form of recreation, push and pull factors and their interplay are important in the choice of destination (Crompton, 1979; Chon, 1993). Push factors are motivational traits inherent in the individual which cause them to make the tourist trip, and pull factors are specific attractive forces relating to the destination. Recreational walking can therefore be characterised by two types of motivation: general motivations to perform the activity, and specific motivations relating to the routes and locations chosen. However, given that walking tourists reflect a range of motivations from challenge, risk and adventure to more sedate needs such as relaxation, push and pull factors will differ depending on individual characteristics and preferences for walking locations.

There are a number of studies in health-related literature which identify 'objectively measured environmental variables' (see Humpel et al., 2002; Saelens et al., 2003; Giles-Corti et al., 2005), that is, characteristics in the walking environment which may increase or decrease the population of walkers using certain routes. Pikora (2003) studied physical and social determinants of walking and cycling participation in Australia, using environmental factors grouped as: functional (gradient, access, path design, surface width, traffic speed and volume), safety (crossings and lighting), aesthetic (architecture, trees and street maintenance) and destination (local facilities and parks). Alfonso (2005) modelled walking needs, using a framework influenced by group, individual, regional and physical environmental variables. The first order of variables (feasibility) was considered most important and must be realised by an individual for them to consider the second variable (safety). Pleasurability was the least important group of factors, in contrast to the motivations inherent in recreational walkers. The urban setting of many route choice studies in the field of health, and the functional nature of many of the walks analysed can explain this. 
In natural settings, both tangible and intangible elements of the environment are considered either objectively or subjectively by individuals. An analysis of activity-based tourist segments by Agapito et al. (2014) indicated that hiking and trekking were highly associated with rural sensory or a nature based experience. The most frequently cited sight-related aspects of the experience were landscape, natural light and diversity of colours, whilst hearing-related sensory elements were predominantly birdsong, wind and the sound of the sea. Higham (1998) acknowledged the emerging trend of tourists becoming more likely to branch away from more established routes and locations, and the rise in wilderness tourism and independent travel. The preference of some tourists for a holistic wilderness experience suggests a different need being met in terms of exposure to certain natural elements associated with locations.

The element of choice is key in understanding preferences for tourist settings. Martin (2008) modelled choices of destination for discretionary tourist travel, by grouping a series of processes: demographics, external influences and 'pre-framing events' - which interact to frame tourist's choices, and their selection of destinations. In turn, activities once at the destination are influenced by both pre-trip factors and on-site influences which occur in situ. This model is relevant to a walking trip as initial choices lead the walker to a destination, but other, perhaps unplanned, forces act when on the walk causing the walker to evaluate the choice of route. Pigram and Jenkins (2006) state that, when understanding recreational choices, making predictions is problematic because of the subjective nature of recreation decisions and because choices can sometimes be bound by constraints, including physical capability, awareness, wealth, time availability and family obligations. Conflicts between participants of different activities and obstructions such as weather are also relevant (Cessford, 2003; Tucker and Gilliland, 2007).

\section{Research Method}

The aim of this study was to understand in detail the differences between people who walk in tourist spaces, their characteristics, preferences and motivations. The research was particularly focused on gaining a broad but detailed picture of behaviour and decision-making of this diverse group of tourists. Twenty three in-depth interviews were undertaken with practitioners who have had long-standing and continued exposure to the needs and wants of walkers. The value of this approach and its outcome is to frame the activity of walking, the nature of its differences and provide important contextual basis for future study. Essentially, whilst it is clear to many that walking is a wide-ranging phenomenon spanning adventure tourism and more general tourism, it is useful to understand more clearly how this segment behaves through the prism of the supply sector's viewpoint from the management of experiences of walking tourists: and whether or not they consider that there are distinct groups or 'types' of people who fundamentally seek different experiences and behave differently.

The human-centred nature of these aims, and the fact that almost all of the interviewees were walkers themselves reflect a pragmatic approach, which places importance on the 
consequences of the research in a real-world perspective (Watkins and Giola, 2015). Their close involvement with the activity means that they 'live within the world' of walkers; a situation which could potentially be construed as bias, but it is that bias itself which offers a credible provider of the emerging themes in inductive research (Charmaz, 2006).

Interviewees were selected on the basis of their connection to and knowledge of the walking tourism market in the UK and were engaged in walking-related occupations including: writers, researchers, countryside and recreation managers, equipment developers, walking planners and group leaders. This selection method is known as purposive sampling (see Patton, 1990) which is focused on developing a frame for the research area. Table 1 details the occupations of the experts interviewed.

\section{INSERT TABLE 1 SOMEWHERE NEAR HERE}

The method of in-depth interviews is a powerful tool to understand the lived experiences of people regarding a particular subject area, rather than testing a hypothesis or discrete evaluation (Seidman, 2013). In simple terms, it is a conversation with a research purpose (Kvale and Brinkman, 2009). A good qualitative interview will achieve breadth and depth in terms of insight into the subject area (Yeo et al., 2013).

The interviews lasted between 60 and 90 minutes, using open questioning, allowing the interviewee to talk freely around the subject area. Recordings were transcribed and coded using NVivo software. The interviews were coded using a 'bottom up' approach (Pidgeon and Turner, 1991), by constructing the codes and identifying their relationship as the transcripts were examined.

The analysis process then drew together codes into a coding tree which stemmed from initial themes relating to the principal aspects of the subject area of recreational walking, differences between walkers, and route choice. These themes diverged and were developed over the course of the interviews as new themes emerged in the analysis process. In some cases, codes became both more nuanced and defined, but the core themes therefore became more illustrated and concrete as they were understood better. The organisation of codes was part of the process, and increased understanding and meaning in the data.

\section{Findings}

\section{INSERT FIGURE 1 SOMEWHERE NEAR HERE}

Figure 1 shows how, over the course of the 23 interviews, a number of themes emerged regarding the experiences walkers seek, how they are characterised by the interviewees and how the research was developed through the analysis process. Topics began under broad headline themes of experiences, characteristics, motivations and behaviour; with extra consideration given to the dynamics of the research and supply side perspectives, as they 
added a further dimension to the analytical process. Over the course of interviews, the differences between walkers began to become sharper in focus: different walking conditions, choices and experiences affect the way that walkers think about and approach the activity; and personal confidence in one's walking ability affects choices. When the final few transcripts were analysed, the complexity of the research subject area had become apparent. The following sections explore the themes as they developed.

\subsection{Initial understanding of the research area}

\section{INSERT FIGURE 2 SOMEWHERE NEAR HERE}

Figure 2 explains the themes and research thought processes emerging from the first step of analysis. Discourse reflected universal motivations for recreational walking: health and wellbeing, relaxation, the escape from the everyday, discovery of surroundings, history, culture and the visual experience. Physical exertion and feelings associated with more challenging forms of walking were also discussed. In some extreme cases, this extended to the most challenging experiences.

'You've got these hundred milers who are in for the slog. They've got two and a half days to do it in.'

The perceived achievability of the walk was discussed. Tangible achievements include reaching a summit, navigational objectives, or literally feeling tired afterwards. Individuals are likely to assess their own ability and fitness, and the relative difficulty of the walk. One respondent suggested that walkers often experience post-activity satisfaction as a 'bath moment', a metaphor for reflecting on their achievement:

'... the entertainment, the outcome comes by getting back...because someone once said to me: 'What's the best bit about walking and I said jokingly: 'It's the bath afterwards, or the pub afterwards'...you know, when you've finished the walk you've got a sense of achievement.'

The speed of walking as a mode of transport was considered unique in comparison to cycling, car and other modes, offering a unique experiential interaction with surroundings. Walking was also considered a social experience, particularly in organised groups as it represents a chance to meet likeminded people, combat loneliness, share an experience and spend valuable time with family and friends.

'There are certain elements about, in terms of relationships, with partners and friends and family, that's the one time they are uninterrupted by the things that they have in normal life. So celebrating those moments is cherished time. There's a powerful health aspect to it, but I think if walking were bad for them they'd still go and do it.'

Solo walking was considered a more insular experience, in which the walker becomes immersed in their external environment with minimal human interference. 
Similarities and differences of individual walkers began to emerge, based on preferences for landscapes. Sensory factors are widely important to choices and the quality of visual attraction offered by routes can be conceived as an 'overall' quality such as a mountainscape, or depend on individual elements such as water, tree cover or a specific point of interest, either natural or man-made. One respondent also noted that visual preference extends to urban spaces, especially in tourist areas because it adds to the overall tourist experience. Tourists are likely to also visit nearby urban areas before or after walks. Seasonal variations in the visual appearance of landscapes are also significant elements of location preference:

'So it's a closeness to nature, and how that changes through the seasons.'

The degree of management on particular routes was another recurring theme. Tourist expectation encompasses a scale ranging from a wilderness experience within relatively untouched surroundings to heavily 'manicured' sites with gravel paths, and prominent facilities. Motivations for wilderness locations include the desire to travel lesser-frequented routes, avoid crowds of people and experience the tranquillity offered by more remote areas. Natural authenticity is a key element of the experience.

Alongside walking-related themes, much insight was gained on the supply perspective, reflecting the diversity of organisations involved in areas such as marketing, transportation and the design of walks. Interviewees were consistent on their observations of walkers' preferences despite this. Understanding more about walkers' varying needs and sustainable visitor management emerged as important areas within circles of practitioners. Ultimately the differences between walkers' thoughts and actions were developing at this stage of the analysis.

\subsection{Exploring confidence: a core theme in the analysis}

\section{INSERT FIGURE 3 SOMEWHERE NEAR HERE}

It became clear that respondents considered segmenting walkers to be more complex than using only demographics and primary motivations for walking. Figure 3 illustrates the development of themes beyond general motivations to walk, showing how experiences gained from walking environments, navigation and the level of engagement of individuals affects their choices and behaviour. A core emergent theme became apparent which transcended many other aspects of the subject area. Many interviewees perceived an intangible and potentially variable level of confidence in recreational walkers, which can explain behaviour and route-choices made.

'We've definitely found confidence to be a major factor and sometimes it needs to be more acknowledged I think. And there are different aspects to that because some of it is about tangible skills: map reading, basic techniques or knowing about equipment 
and so on. And other aspects of confidence are quite intangible and almost about cultural expectations.'

Within the numerous instances where interviewees discussed confidence, the primary individual characteristics affecting walkers' level of confidence were reduced to:

- Their level of experience of recreational walking (a result of the previous amount of walking undertaken, and the level of challenge involved in those walks)

- Their technical ability (for instance knowing 'how to walk' on difficult surfaces, challenging, longer distance and hill walks)

- Their navigational ability (the ability to read and follow maps, and negotiate the environment using physical aspects of the landscape or land marks)

- Their physical ability (personal fitness and level of stamina).

Figure 4 describes the influences confidence, ability and experience have on each other. If an individual's level of confidence is considered as a continuum, the research findings suggest that people with high levels of experience and ability are likely to be more confident and attempt walks of greater distance and difficulty.

\section{INSERT FIGURE 4 SOMEWHERE NEAR HERE}

A consensus amongst interviewees indicated that individuals who are less confident require accurate, uncomplicated information on navigation, landmarks and transportation.

'The barriers that they faced and the things they were telling us was that they needed better information and much more information. They needed somebody to help them to start with whether it was a guided walk or whether it was a bit of training to use a map and compass so it is - it's building up their confidence.'

These requirements apply to tourists who are infrequent walkers, using walking as a vehicle for sightseeing, although there are other contributory factors. The relative safety of having others make route-choice decisions characterises this end of the confidence scale. There were indications that confidence increases by gaining walking experience, learning from more experienced walkers, engaging in decision-making on walks and walking solo.

'Because they know it's up to them to take the lead or to get themselves out of trouble or so on. And if there's someone else more experienced they sometimes don't develop the confidence because it's always left to the same person to read the maps, read the routes, whatever. So I think beyond that there's quite a lot of complex dynamics going on there...that can make people more or less confident.'

Interviewees suggested that building confidence to a higher level often stimulates an experiential desire for more adventurous forms of walking, the motivation to seek new challenges and risks, venture further, and in some cases lead others. A long-distance 
walkers' group manager discussed how group members progress to leading the group themselves:

'So the leader will go out and reccy a walk. And then he'll take a party of whoever turns up. And it wasn't until I'd been in the group 4 or 5 years until I felt confident enough to lead a walk.'

In some circumstances however, walkers experience 'false confidence'. They then potentially face difficulties in challenging conditions: at altitude or when weather changes.

'The casual walkers probably don't. You do occasionally see people who are trying to get along Striding Edge [a challenging route in the English Lake District] in winter on the snow and they are just wearing trainers'

Despite confidence appearing to be the most significant differentiator of individuals from the data, it still remains an intangible quality. From many of the respondents' opinions, experience appears to be interrelated with gaining confidence.

\title{
4.3 Casual and serious walkers
}

\section{INSERT FIGURE 5 SOMEWHERE NEAR HERE}

A second significant theme emerged from the data which also relates to confidence. A number of respondents used the terms 'casual' and 'serious' without being prompted by the interviewer to differentiate walkers. Figure 5 demonstrates how the analysis began to characterise these differences. A recreation manager from the Lake District National Park Authority, encapsulated general characteristics of these two groups when discussing information needs.

\begin{abstract}
'We worked with a consultancy company and they did a needs and preference research. And they categorised all the different types of users and one of their categories was serious and casual walkers. So the needs and preferences of each of them came out to be quite different. And I think and it's my opinion but you look at serious walkers - you think of hill walkers. It's not something that they just do as part of a day out or as part of a general holiday. It's something that is their primary purpose especially when you're in a national park like this. The reasons that people come here are different.'
\end{abstract}

In some cases the distinction was used to describe traits of individuals based on their attitudes to walking as a recreational activity. The two categories provide a means of conceptualising the difference between: a group of people who consider walking an important recreational pursuit to which they devote a reasonable amount of time and energy in their lives; and another group of people who do not necessary pursue walking as a regular activity, engaging in walks sporadically or for sightseeing at a destination. For serious walkers, the strenuous nature of the walks they choose and the inclusion of hills and mountains, are indicative of 
their preferences. The interviews also strongly suggested that the devotion of serious walkers encompasses attitudes to weather, the environment, skills and equipment, and to other areas of their lives.

'They don't seem to mind even if it's wet. That's when the serious walkers differ. They go out rain or shine.'

The use of a map to plan the walk adds to the holistic experience:

'I think. A lot of the fun of walking for the more committed is that planning process mug of coffee maps out. Where are we going to go. How are we going to plan this?'

Table 2 summarises some characteristics which respondents associated with serious and casual walkers.

\section{INSERT TABLE 2 SOMEWHERE NEAR HERE}

Several respondents also referred to a serious walker's 'identity', hinting at a visible subculture of recreationists; the high specification clothing represents a 'uniform' in this sense to identify a 'walker'. The image of being serious was discussed further by one interviewee:

'... a completely novice backpacker would buy a brand new shiny back pack. And then would come across really experienced back packers whose stuff was all worn, and then they would purposefully rough up their equipment (...) I have actually heard...it's more of a climbing thing I think, (...) of people marking their equipment so it looks as if it's not new. To make them look more experienced.'

'Serious walkers' value the challenge of the route, long distances and steep gradients, and in some cases the time taken (this reflects when walking becomes a sport). In some cases this extends to longer term goals by completing a checklist of mountain peaks (for example, to walk all of the Scottish 'Munros'). Other important parts of the experience reflect feelings of the need for comfort or safety, although for more serious walkers this may be traded off for risk and adventure. For casual walkers, comfort also reflects elements such as being close to toilets, smooth path surfaces, shops and refreshments.

\subsection{Complexities of the research perspective}

\section{INSERT FIGURES 6 AND 7 NEAR HERE}

As the analysis process progressed, the nuanced nature of categorisation emerged; through consideration of the various niches of more dedicated walks: long-distance walking, hill walking, rambling clubs or the more technical, challenging mountain walks outside of the UK; and at the other end of the scale more functional walks which could still be 'pleasurable', 'health walks' for people unused to walking, and guided tours. 
It was suggested that the concept of 'serious walking' may be indicative of circumstances. References were made to situational variables such as lack of available time, which affect the ability of individuals to walk often. Indeed, the proximity of an individual's residence to suitable locations to go walking may impact their current 'status' as a serious or casual walker:
'Absolutely...well it's pretty much the same thing but it depends on their incumberences and their time of life. How much time they have how far away he country is. Because you might have somebody...let's call them a scrambler and put them at category five. The demanding type. Yet because of his job he's now forced to live in Cambridge. And that means that it's 250 miles to the next...acceptable...country...in his book. And that might be something that he can't do very often. Whereas in his previous job he lived in Penrith and went up the Dales every day.'

This idea of fluidity between casual and serious walking became a conceptual question suggesting that there could not be two 'boxes' which are completely separate, in which different individuals fall into:

'Yes. It's obviously very difficult to have a dividing line. The lines are very blurred. There's a lot of overlap.'

It also transpired that there may well be a degree of mobility between groups. One person could engage in 'casual' and 'serious' walks at different times.

'One particular person might do a very casual walk one day dog walking, or just walking to the shops. And then at the weekend they're doing a round of five Munros or something. Very much at the serious end. And they're the same person.'

It was suggested that becoming a serious walker can be an aspirational movement. This idea of progression suggests a casual-serious continuum rather than discrete groups, in which it might be difficult to pinpoint where exactly a walker changes from being casual to serious.

Thus, although many respondents could provide a number of definitive characteristics which separated their idea of casual and serious walkers, there must be caution in using the terms as distinct definitions. It may be easy to generalise to an extent, but one must view the potential of using such categories as a useful framework for study, observation and to use practically in providing resources for walkers, rather than a distinct and closed division of people who walk. That also is the nature of segmentation in tourism.

Collective characteristics reflective of all walkers were also discussed. For instance, walkers were considered to have a relatively high environmental awareness. It was also suggested that during young adulthood, more adventurous outdoor activities are attractive whilst walking represents a less strenuous activity in later life - confidence in one's ability may play a part in this. However it became apparent that motivations and preferences varied between 
walkers, in terms of their interest in the landscape, preferred route characteristics, and the level of management of the routes they choose.

Regarding route-choice, a question was raised over whether a decision chain exists for walkers, either purely based on experiential expectations or partially by situational factors. The interview findings suggest that a hierarchy of factors interact to determine eventual route-choice. Initial prompts include suggestions by friends to walk certain routes or visit locations, previous experiences, or specific points of interest seen in books or other forms of media. In some cases a specific purpose such as walking a dog, or finding somewhere to eat influence choice of route.

Situational factors affect route choice, both before and during walks. Rain, wind and cold temperatures can be a deterrent. Certain decision elements relate to practical considerations including: transport access to certain routes, the distance of the intended walk from home or a holiday base and the availability of information about how to access a particular walk. Physical barriers such as stiles, farms, fences or roads are common in situ deterrents which also affect route-choice. More general dislikes include conflicts with other users such as horse riders or cyclists, encountering cattle, large amounts of litter on routes and having to negotiate barbed wire fences. Perceptions of these issues range from mild irritation to more major disturbances which can adversely influence overall satisfaction with the walking experience. Other problems, such as extremely poor surfaces, can completely stop the walk. Personal safety and security are additional concerns for some walkers, both in rural and urban locations. The more obvious attributes included demographic differences (age, gender, socio-economic variations and ethnicity).

Wider factors in a decision chain can be specific to individuals or groups of walkers. Clearly, route-choices are made either by one individual or are based on the preferences and constraints of a number of people. One respondent suggested that although the balance of individual requirements determines the group dynamics with respect to route choice, certain individuals may exert greater influence than others. The presence of younger children or adults with limited mobility within groups can entail greater consideration of the routechosen, in order to make it achievable.

A further element relates to specific purposes which need to be fulfilled on walks. Sometimes main or subsidiary purposes of walks are more functional such as walking to work or exercising a dog. This tests conceptual boundaries of defining walks for recreation or tourism, as it is debatable whether the walk is functional, for pleasure, or both. Several respondents emphasised the importance of deriving pleasure from functional walking. This is a conceptual matter, as a walk may be functional to one person, yet to another their route may be chosen to make a functional walk more enjoyable, rather than for convenience. Ultimately this decision is subjective to the individual.

\section{Discussion and conclusion}


This study has provided an in-depth exploration of the observations and experiences of professionals involved in the supply of outdoor walking resources in areas of adventure tourism. The findings indicate that practitioners see the activity as much more diverse than a singular activity which is often treated with a one-size-fits-all approach in research in the area. Walking is a universal tourist activity which bridges adventure tourism and other forms of tourism, and there are numerous ways in which it can be subdivided, based on characteristics, motivations and walking preferences.

The research indicated that the terms 'casual' and 'serious' are useful and more tangible categories to differentiate walkers, particularly in the eyes of practitioners who are tasked with meeting the needs of tourists. The work of Stebbins is relevant here. Originally, Stebbins (1982) produced a conceptual statement on serious leisure, noting at the time the trend towards people working less and a growing minority of people spending more time indulging in leisure activities deemed as 'serious'. Walking for recreation fulfils this definition if one considers the current market for long-distance walking, 'peak-bagging', mountaineering or walking holiday tours; forms of walking which 'fit' the adventure tourism study area more closely than others. Stebbins (1997) later noted a further classification of activity: casual leisure. Casual leisure is often discussed as a foil for describing or illuminating serious leisure and requires 'little more than minimal skill, knowledge or experience' (Stebbins, 2004). Stebbins initially outlined six 'types' of casual leisure, three of which are relevant to the derived experience and motivations for a more 'casual form of walking': active entertainment, sociable stimulation and sensory stimulation. These criteria fit with walkers who may walk as part of a more general holiday in an adventure tourism location. Do casual walkers fall outside of the adventure tourism spectrum? Probably, but the resources and locations involved are often the same. Furthermore, as walking is important to all tourism forms, they require equal attention to definition. Regarding the 'aspirational' element of serious walking, proximity is important in drawing people together in recreational relationships (Argyle, 1981), and the main criteria for being inducted as a serious walker is to be in the locations, close to the other serious walkers. More attention to the aspirational dimension would be beneficial to future research.

The other key finding of the interviews suggested that confidence is one significant differentiator of individuals and the walks they choose, and the challenge for researchers is to understand exactly how this partially intangible concept manifests in walkers and walking behaviour. Confidence is generally only a small part of conceptual models in tourism research. Pearce and Lee (1995) studied an array of different categories of aspects drawn from touristic experience, including romance, stimulation, isolation and autonomy. Confidence falls into one factor group category (self-development) as 'Gaining a sense of self-confidence'. Self-esteem and identity are important elements of Pomfret's (2006) conceptual framework for mountaineers and if one considers mountaineering at the 'serious' end of the walking spectrum, it is suggested that confidence is part of the mechanism which determines these qualities. However, that spectrum is fluid, and Beedie and Hudson (2003) suggest that there is also no longer a gradual promotion from low level walking to more adventurous activity, as trends indicate a reduction in independent operations within 
mountain-scapes, due to a higher degree of organisation of activities. To understand confidence in both walking and tourism activities further, more overlap between psychology and the field of tourism would be useful.

The study provides a conceptual exploration of the recreational walking market, producing insights into the differences between walkers in their motivations and route-choices, which outdoor recreation practitioners use to focus the supply of resources, information and marketing. Future research should look at factors affecting groups and route-choice using empirical study, to better form segments and remove some of the grey conceptual areas still present. The research showed that many practitioners use their own categories but the collective knowledge base would benefit by understanding segments and their characteristics further. Whilst there is some potential bias in using interviews with practitioners, much depth on this subject area has been gained, due to them being immersed in the 'world' of walkers. A more direct study on walkers themselves would be equally valuable.

\section{References}

Agapito, D., Valle, P. and Mendes, J. (2014). "The sensory dimension of tourist experiences: Capturing meaningful sensory-informed themes in Southwest Portugal." Tourism

Management 42(0): 224-237.

http://www.sciencedirect.com/science/article/pii/S0261517713002094

Alfonzo, M. A. (2005). "To Walk or Not to Walk? The Hierarchy of Walking Needs." Environment and Behavior 37(6): 808-836 doi: 10.1177/0013916504274016

Anable, J. and Gatersleben, B. (2005). "All work and no play? The role of instrumental and affective factors in work and leisure journeys by different travel modes." Transportation Research Part A: Policy and Practice 39(2): 163-181.

Argyle, M., Furnham, A. and Graham, J. A. (1981). Social situations, Cambridge: Cambridge University Press doi: 0.1017/CBO9780511558283

Beedie, P. and Hudson, S. (2003). "Emergence of mountain-based adventure tourism." Annals of Tourism Research 30(3): 625-643. doi:10.1016/S0160-7383(03)00043-4

Brandenburg, C. H. and Ploner, A. (2002). "Models to Predict Visitor Attendance Levels and the Presence of Specific User Groups." Paper presented at Monitoring and Management of Visitor Flows in Recreational and Protected Areas Conference, Vienna 2002

Bryant, B. E. and Morrison, A. J. (1980). "Travel market segmentation and the implementation of market strategies." Journal of Travel Research 18(3): 2-8. doi: $10.1177 / 004728758001800301$ 
Charmaz, K. (2006). "Constructing grounded theory: A practical guide through qualitative analysis (Introducing Qualitative Methods Series)." New York: SAGE Publications Ltd

Chon, K.-S. (1993). "Understanding recreational traveler's motivation, attitude and satisfaction." Tourism Review. 44(1): 3-7. http://dx.doi.org/10.1108/eb058009

Cheung, S. C. (1999). "The meanings of a heritage trail in Hong Kong." Annals of Tourism Research 26(3): 570-588. http://mmv.boku.ac.at/refbase/files/brandenburg_christi-2002models_to_predict_vi.pdf

Connell, J. (2006). "Medical tourism: Sea, sun, sand and... surgery." Tourism Management 27(6): 1093-1100. doi:10.1016/j.tourman.2005.11.005

Crompton, J. L. (1979). "Motivations for pleasure vacation." Annals of Tourism Research 6(4): 408-424. doi:10.1016/0160-7383(79)90004-5

Cutler, S. Q., Carmichael, B. and Doherty, S. (2014). "The Inca Trail experience: Does the journey matter?" Annals of Tourism Research 45: 152-166. doi:10.1016/j.annals.2013.12.016

Dann, G. M. S. (1977). "Anomie, ego-enhancement and tourism." Annals of Tourism Research. 4(4): 184-194. doi:10.1016/0160-7383(77)90037-8

Davies, N. J., Lumsdon, L. M. and Weston, R. (2012). "Developing recreational trails: Motivations for recreational walking." Tourism Planning \& Development 9(1): 77-88. doi: $10.1080 / 21568316.2012 .653480$

Davies, N. J. and Weston, R. (2015). "Reducing car-use for leisure: Can organised walking groups switch from car travel to bus and train walks?" Journal of Transport Geography 48: 23-29 doi: 0.1016/j.jtrangeo.2015.08.009

Den Breejen, L. (2007). "The experiences of long distance walking: A case study of the West Highland Way in Scotland." Tourism Management 28(6): 1417-1427. doi:10.1016/j.tourman.2006.12.004

Dickson, T. J. and Gray, T. L. (2011). Risk management in the outdoors: A whole-oforganisation approach for education, sport and recreation, Cambridge University Press. isbn: 9780521152310

Ewert, A. (1987). "Research in outdoor adventure: Overview and analysis." Bradford Papers Annual 2: 15-28. http://www.d.umn.edu/ kgilbert/ened55601/Readings/Adventure\%20Research\%20Overview\%20-\%20Ewert\%201987.pdf

Ewert, A. W. (2000). Trends in adventure recreation: Programs, experiences, and issues. Proceedings of the 5th outdoor recreation and tourism trends symposium. 2000 
Frochot, I. (2005). "A benefit segmentation of tourists in rural areas: a Scottish perspective." Tourism Management. 26(3): 335-346. doi:10.1016/j.tourman.2003.11.016

Giles-Corti, B., Broomhall, M. H., Knuiman, M., Collins, C., Douglas, K., Ng, K. Lange, A. and Donovan, R. J. (2005). "Increasing walking: How important is distance to, attractiveness, and size of public open space?" American Journal of Preventive Medicine 28(2, Supplement 2): 169-176. DOI:10.1016/j.amepre.2004.10.018

Higham, J. (1998). "Sustaining the physical and social dimensions of wilderness tourism: the perceptual approach to wilderness management in New Zealand." Journal of Sustainable Tourism 6(1): 26-51. doi: 10.1080/09669589808667300

Highlands and Islands Enterprise (1996), The Economic Impacts of Hill-walking, Mountaineering and Associated Activities in the Highlands and Islands of Scotland. Inverness: HIE.

Hill, E., Goldenburg, M. and Freidt, B. (2009). "Benefits of Hiking: A Means-End Approach on the Appalachian Trail." Journal of Unconventional Parks, Tourism \& Recreation Research 2(1): 19-27. doi: http://journals.radford.edu/index.php/JUPTRR/article/view/8

Humpel, N., Owen, N. and Leslie, E. (2002). "Environmental factors associated with adults' participation in physical activity: A review." American Journal of Preventive Medicine. 22(3):188-199. PMID: 11897464

Iso-Ahola, S. E. (1982). "Toward a social psychological theory of tourism motivation: A rejoinder." Annals of Tourism Research. 9(2): 256-262. doi:10.1016/0160-7383(82)90049-4

Jacob, G. R. and Schreyer, R. (1980). "Conflict in Outdoor Recreation: A Theoretical Perspective." Journal of Leisure Sciences 12(4): 368-380. http://www.webpages.uidaho.edu/Ethics/Lessons/L_13/ConflictOutdoorRec1.pdf

Kay, G. and Moxham, N. (1996). "Paths for whom? Countryside access for recreational walking." Leisure studies 15: 171-183. doi: 10.1080/026143696375594

Kvale, S. and Brinkman, S. (2009) InterViews: Learning the Craft of Qualitative Research Interviewing London: SAGE Publications ISBN: 9781452275727

Lepp, A. and D. Herpy (2015). "Paddlers' level of specialization, motivations and preferences for river management practices." Journal of Outdoor Recreation and Tourism 12: 64-70 doi:10.1016/j.jort.2015.11.008

Lieber, S. R. and Fesenmaier, D. R. (1984). "Modelling recreation choice: A case study of management alternatives in Chicago." Regional Studies 18(1): 31-43. doi: $10.1080 / 09595238400185031$ 
Lumsdon, L. and Spence, J. (2002). Rationale and design of urban recreational walking trails in several cities in the UK. Paper presented at Walk 21 - 3rd Conference: Steps Towards Livable Cities, San Sebastian, Spain. 9-10 May

Manning, R., Valliere, W., Minteer, B. Wang, B. and Jacobi, C. (2000). "Crowding in Parks and Outdoor Recreation: A Theoretical, Empirical and Managerial Analysis." Journal of Park and Recreation Administration 18(4): 57-72.

http://www.uvm.edu/parkstudieslaboratory/publications/Crowding_in_Parks.PDF

Martin, D. (2008). "Grounded theory of international tourism behaviour: Building systematic propositions from emic interpretations of Japanese travellers visiting the USA." In Tourism management: Analysis, behaviour and strategy Edited in Woodside, A. G. and Martin, D. (Eds): 62-92. Boston: CABI

McKercher, B. (1996). "Differences between Tourism and Recreation in Parks." Annals of Tourism Research 23(3): 563-575. doi:10.1016/0160-7383(96)00002-3

McLean, D. D., Hurd, A. R. and Rogers, N. B. (2008). Kraus' Recreation and Leisure in Modern Society, Jones and Bartlett Publishers. ISBN-13: 9781284034103

McNamara, K. E. and Prideaux, B. (2010). "Experiencing 'natural' heritage." Current Issues in Tourism 14(1): 47-55. doi: 10.1080/13683500.2010.492852

Millonig, A. and Gartner, G. (2009). "Ways of walking-developing a pedestrian typology for personalised mobile information systems." Edited in Gartner, G. and Rehrl, K. Location Based Services and TeleCartography II, 79-94. Berlin: Springer: doi: 10.1007/978-3-54087393-8_6

Molera, L. and Albaladejo, I. P. (2007). "Profiling segments of tourists in rural areas of

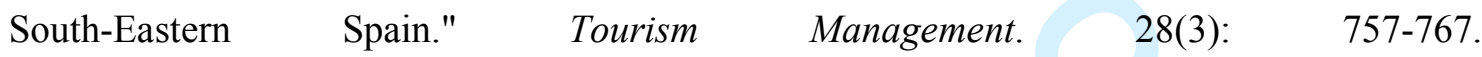
doi:10.1016/j.tourman.2006.05.006

Moscardo, G. (1996). "Mindful visitors: Heritage and tourism." Annals of Tourism Research 23(2): 376-397.doi:10.1016/0160-7383(95)00068-2

Murray, M. and Graham, B. (1997). "Exploring the dialectics of route-based tourism: the Camino de Santiago." Tourism Management 18(8): 513-524. doi:10.1016/S02615177(97)00075-7

Orellana, D., Bregt, A. K., Ligtenberg, A. and Wachowicz, M. (2012). "Exploring visitor movement patterns in natural recreational areas." Tourism Management 33(3): 672-682. doi:10.1016/j.tourman.2011.07.010 
Patton, M. Q. (1990). Qualitative Evaluation and Research Methods (2nd ed). Newbury Park, CA: Sage Publications, Inc. http://psycnet.apa.org/psycinfo/1990-97369-000

Pearce, P. L. and Lee, U.-I. (2005). "Developing the travel career approach to tourist motivation." Journal of Travel Research 43(3): 226-237. doi: 10.1177/0047287504272020

Pidgeon, N. F., Turner, B. and Blockley, D. I. (1991) "The use of Grounded Theory for Conceptual Analysis in Knowledge Elicitation”, International Journal of Man-Machine Studies 35.2 (1991): 151-173. doi:10.1016/S0020-7373(05)80146-4

Pigram, J. J. J. and Jenkins, J. M. (2006). Outdoor Recreation Management. Abingdon, Routledge. ISBN-10: 0415365414

Pikora, T., Giles-Corti, B., Bull, F., Jamrozik., K. and Donovan, R. (2003). "Developing a framework for assessment of the environmental determinants of walking and cycling." Social science \& medicine 56(8): 1693-1703. doi:10.1016/S0277-9536(02)00163-6

Pomfret, G. (2006). "Mountaineering adventure tourists: a conceptual framework for research." Tourism Management 27(1): 113-123. doi:10.1016/j.tourman.2004.08.003

Pomfret, G. and Bramwell, B. (2014). "The characteristics and motivational decisions of outdoor adventure tourists: a review and analysis." Current Issues in Tourism: 1-32. doi: $10.1080 / 13683500.2014 .925430$

Reynolds, P. C. and Braithwaite, D. (2001). "Towards a conceptual framework for wildlife tourism." Tourism Management 22(1): 31-42. doi:10.1016/S0261-5177(00)00018-2

Saelens, B. E., Sallis, J. F., Black, J. B. and Chen, D. (2003). "Neighborhood-based differences in physical activity: an environment scale evaluation." American journal of public health. 93(9): 1552-1558.

Seidman, I. (2013). Interviewing as Qualitative Research: A Guide for Researchers in Education and the Social Sciences, New York: Teachers College Press. ISBN-10: 0807746665

Sharpley, R. and Jepson, D. (2011). "Rural tourism: A spiritual experience?" Annals of Tourism Research 38(1): 52-71. doi:10.1016/j.annals.2010.05.002

Stebbins, R. A. (1982). "Serious Leisure: A Conceptual Statement." The Pacific Sociological Review 25(2): 251-272. doi: 10.2307/1388726

Stebbins, R. A. (1997). "Casual leisure: a conceptual statement." Leisure studies 16(1): 17 25. doi: 10.1080/026143697375485 
Stebbins, R. A. (2004). "Pleasurable aerobic activity: A type of casual leisure with salubrious implications" World Leisure Journal 46(4): 55-58 doi: 10.1080/04419057.2004.9674374

Tomkins, J. (1990). "Recreation and the forestry commission: The case for multiple-use resource management within public forestry in the U.K." Journal of Environmental Management 30(1): 79-88. doi:10.1016/0301-4797(90)90038-X

Torkildsen, G. (2005). Leisure and Recreation Management, Routledge. ISBN-10: 041922940X

Tribe, J. (1997). "The indiscipline of tourism." Annals of Tourism Research 24(3): 638-657. doi:10.1016/S0160-7383(97)00020-0

Watkins, D. and Gioia, D. (2015). Mixed Methods Research, Oxford University Press, USA. ISBN-10: 0199747458

Weber, K. (2001). "Outdoor adventure tourism: A Review of Research Approaches." Annals of Tourism Research 28(2): 360-377. doi:10.1016/S0160-7383(00)00051-7

Wolf, I. D. and T. Wohlfart (2014). "Walking, hiking and running in parks: A multidisciplinary assessment of health and well-being benefits." Landscape and Urban Planning 130: 89-103. doi:10.1016/j.landurbplan.2014.06.006

Yeo, A., Legard, R., Keegan, J., Ward, K., McNaughton Nicholls, C., and Lewis, J. (2013). "In-depth Interviews." In Qualitative Research Practice: A guide for social science students and researcher. J. Ritchie, J. Lewis, C. McNaughton Nicholls and R. Ormston. London, SAGE. ISBN-10: 0761971106 
Table 1: Occupations of interviewees

\begin{tabular}{|ll|}
\hline Walking-related occupation & Number \\
Professional writers of walking guides & 3 \\
$\begin{array}{l}\text { Producer of walking route leaflets } \\
\text { Academic researchers }\end{array}$ & 1 \\
$\begin{array}{l}\text { Countryside and recreation managers for local authorities, } \\
\text { countryside services and Forest Enterprise }\end{array}$ & 4 \\
Walking equipment marketing experts & 2 \\
$\begin{array}{l}\text { National and regional executives of the Rambler's Association } \\
\text { and Long Distance Walker's Association (national walking } \\
\text { groups) }\end{array}$ & 2 \\
$\begin{array}{l}\text { Editor of popular UK walking magazine } \\
\text { Walking holiday and accommodation providers }\end{array}$ & 1 \\
Urban walkability expert & 3 \\
Large walking events organiser & 1 \\
Health walk co-ordinator (Natural England) & 1 \\
National access forum representative from the Institute of Public & 1 \\
Rights of Way and Access Management (IPROW) & 1 \\
Sustainable transport campaigner & 1 \\
\hline
\end{tabular}


Table 2: Characteristics used to describe casual and serious walkers

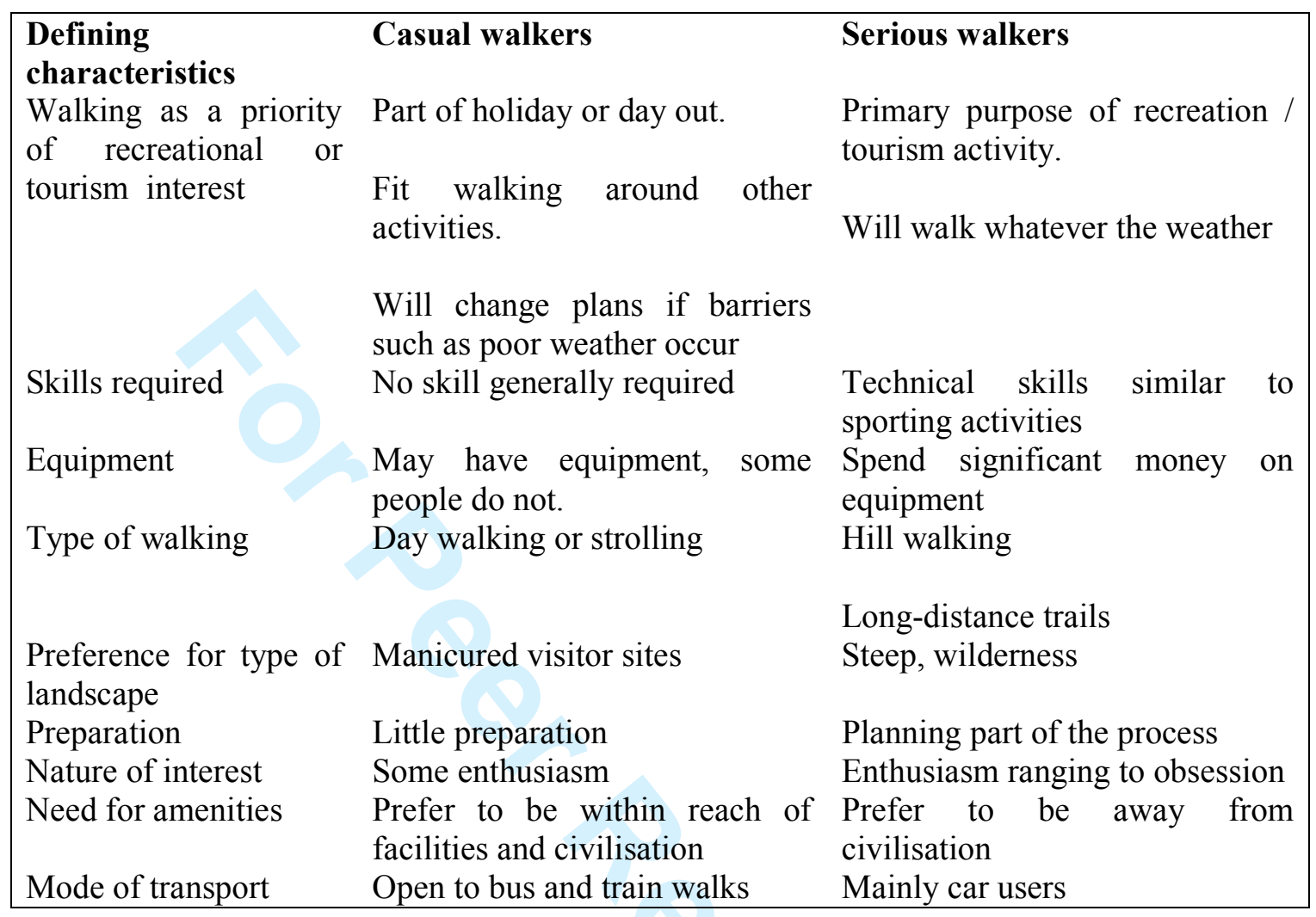


Figure 1: Stages of interview analysis and emergent themes

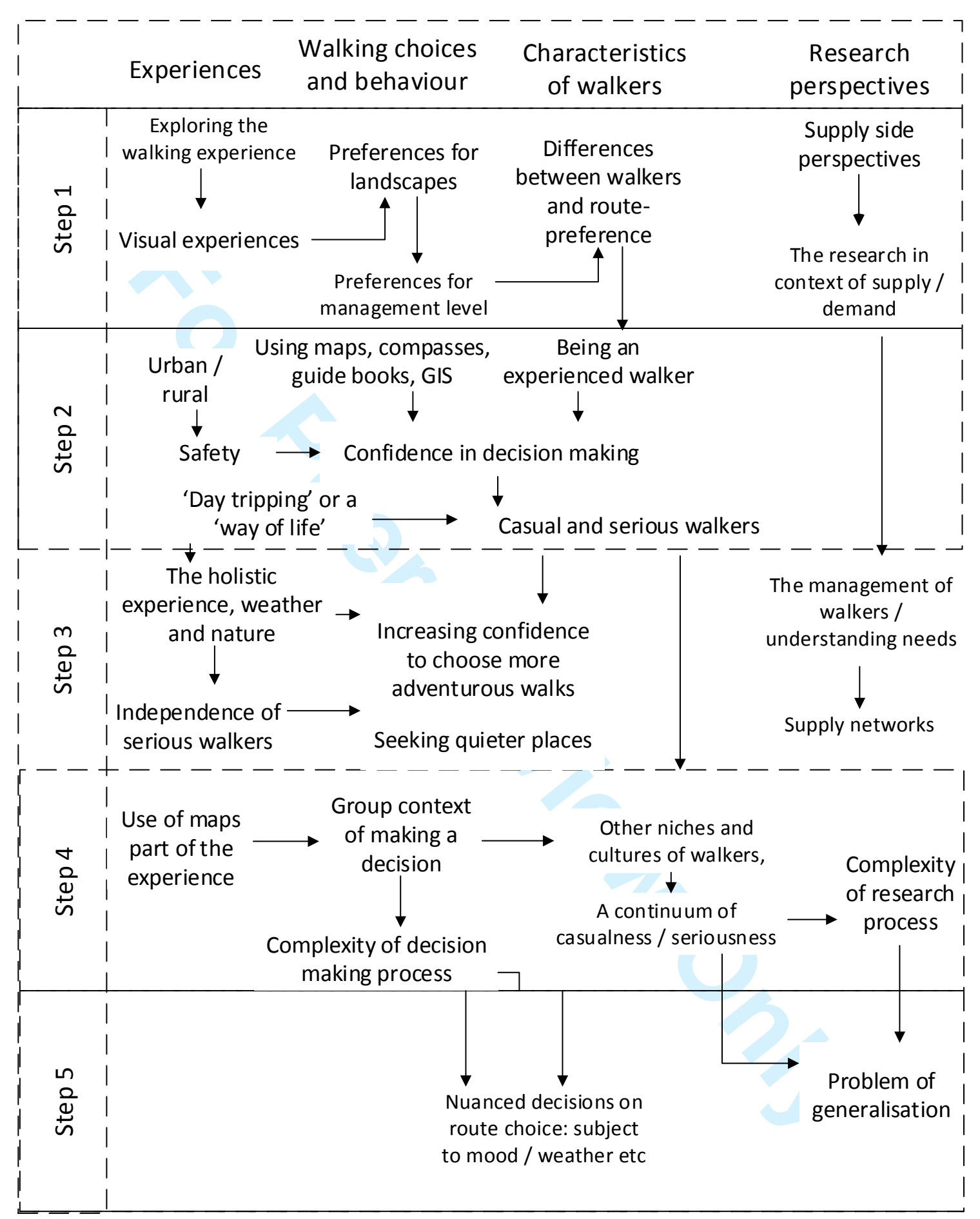


Figure 2: First step of analysis: emergent themes

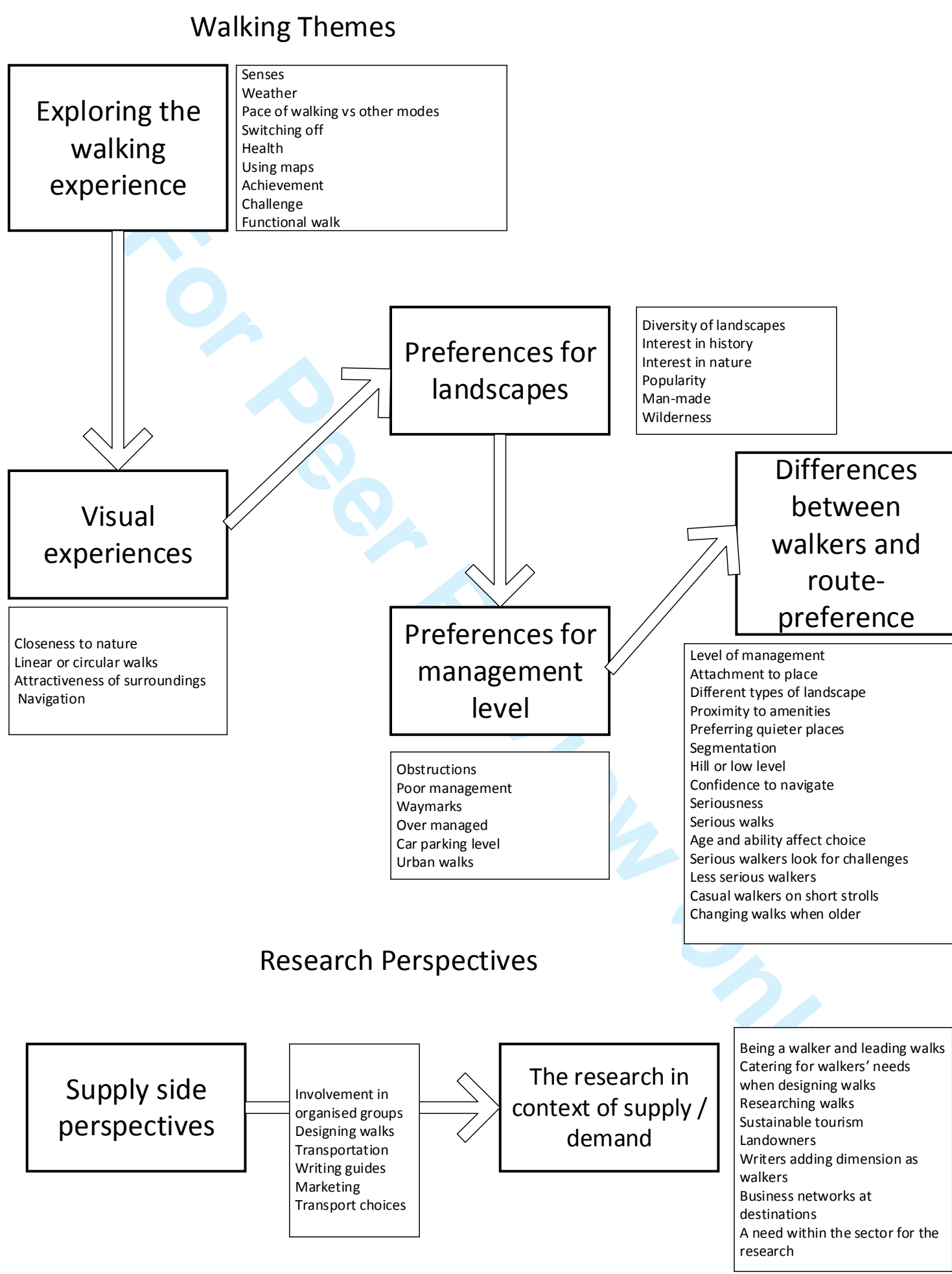

URL: http://mc.manuscriptcentral.com/ranz Email: neil.carr@otago.ac.nz 
Figure 3: Second step of analysis: emergent themes

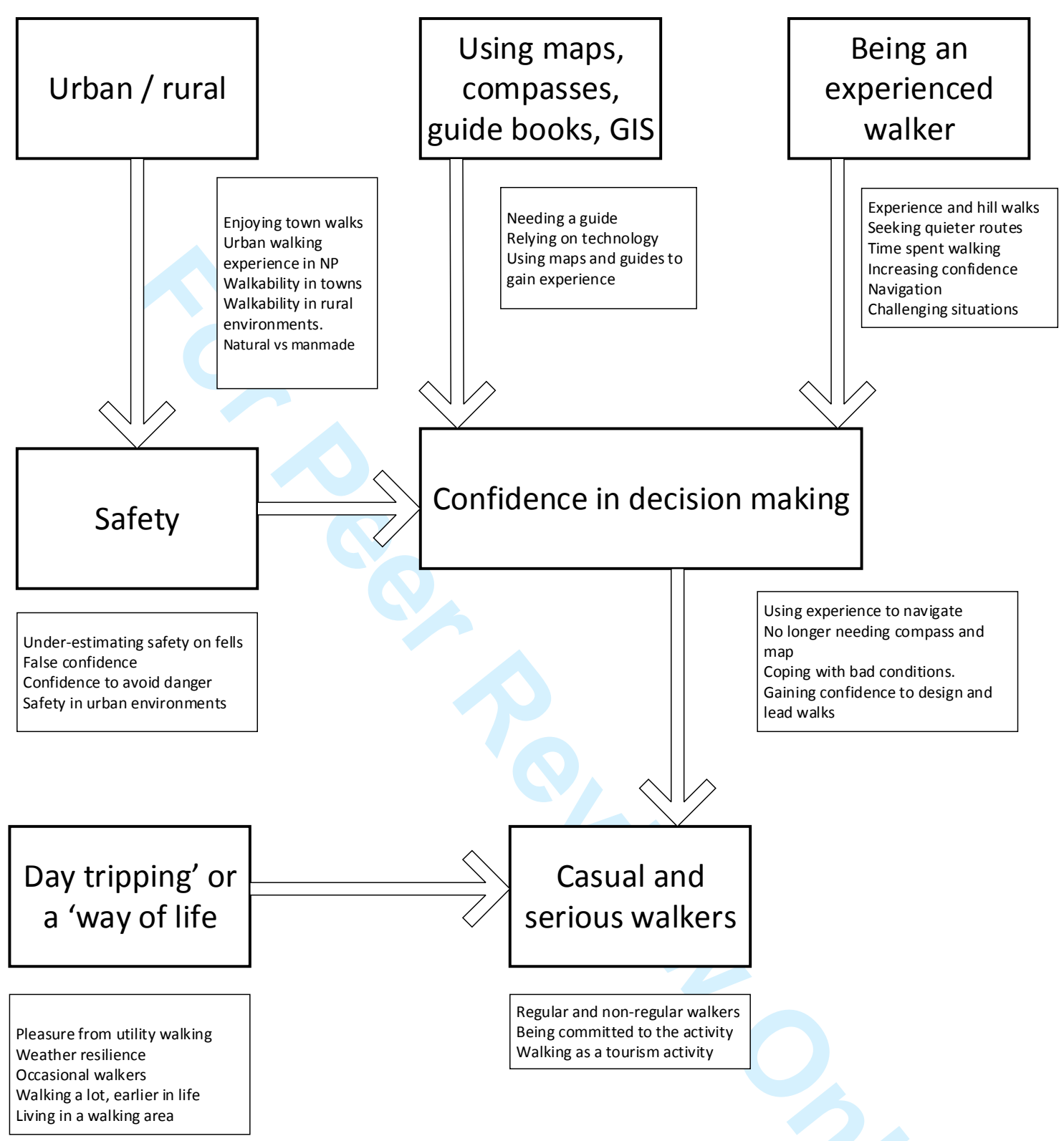


Figure 4: Relationships between walking related attributes

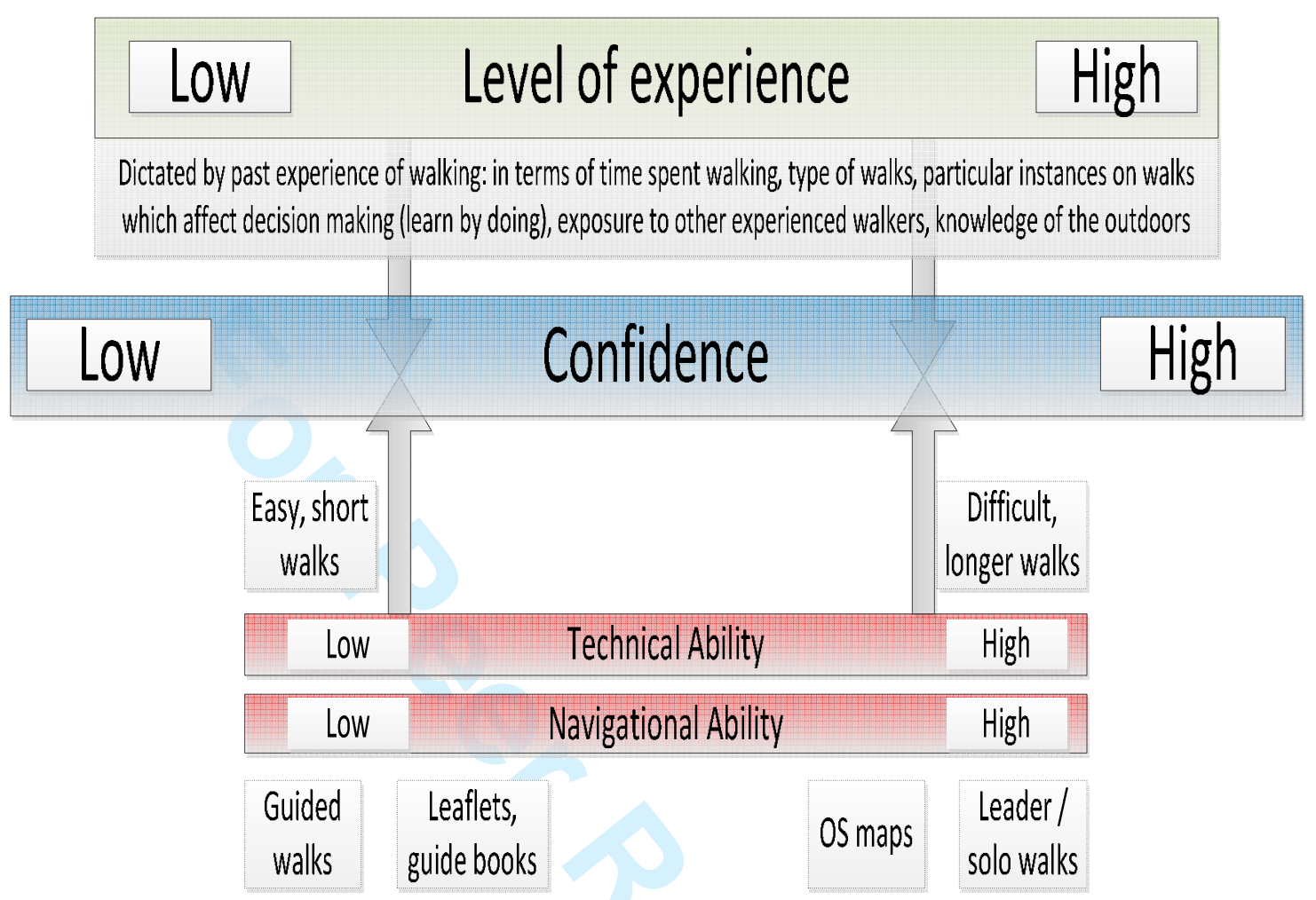


Figure 5: Third step of analysis: emergent themes

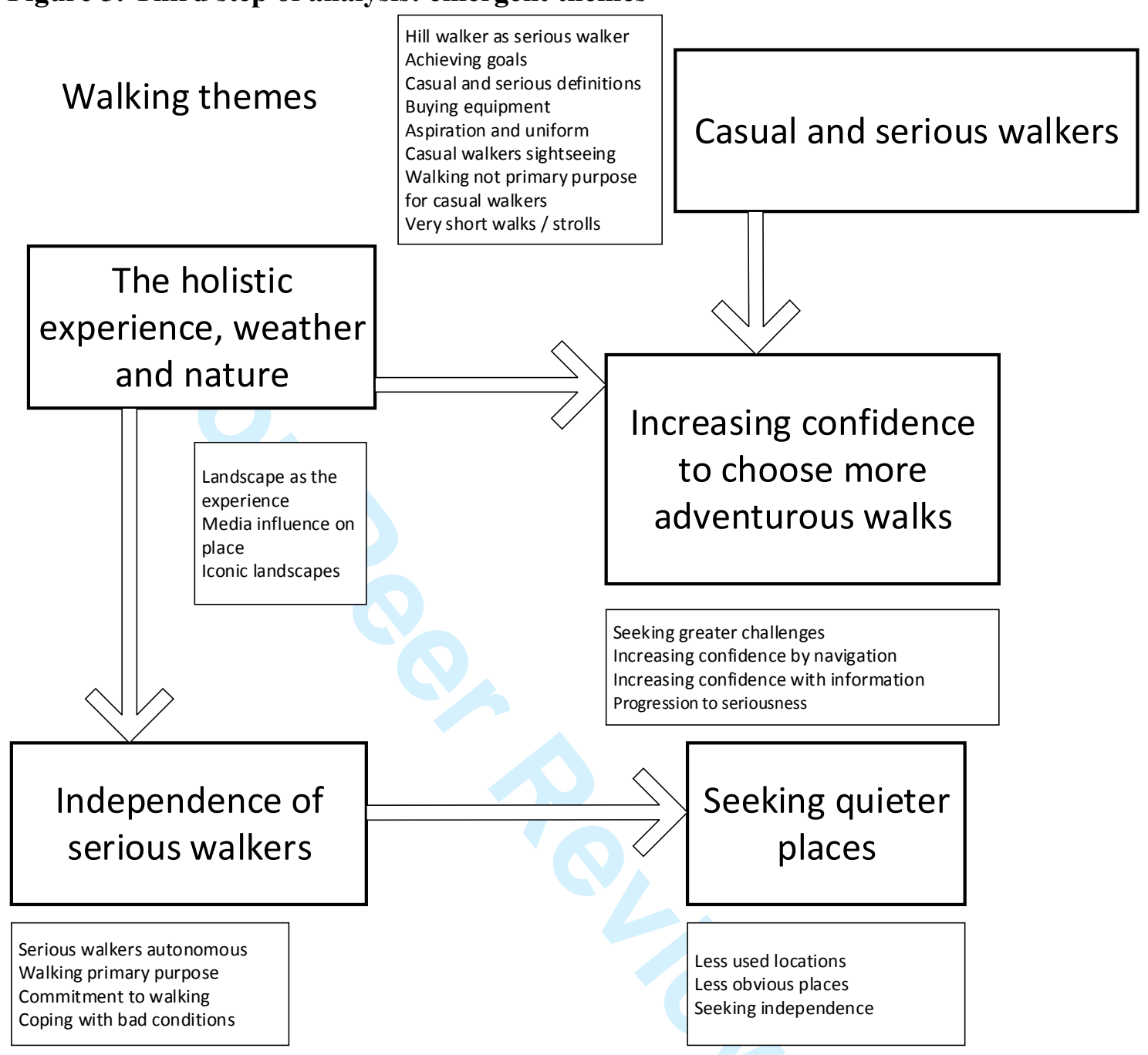

Research Perspectives

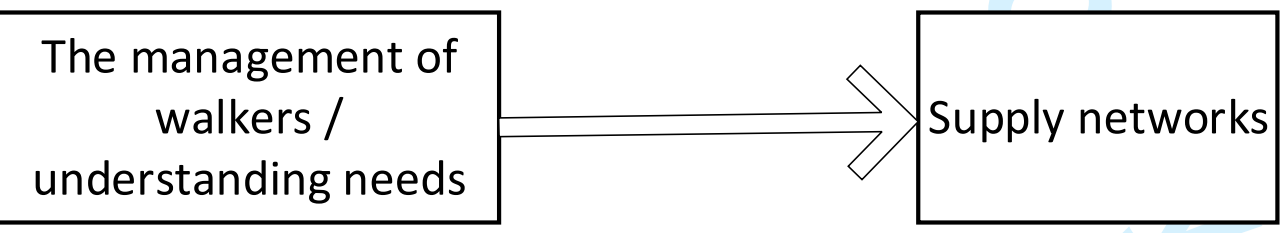

Facilitating needs of walkers

Ensuring access and inclusion

Different needs for casual and serious walkers

Information and interpretation

Confidence in access

Understanding decision making

Management of environment

Access for all 
Figure 6: Fourth step of analysis: emergent themes

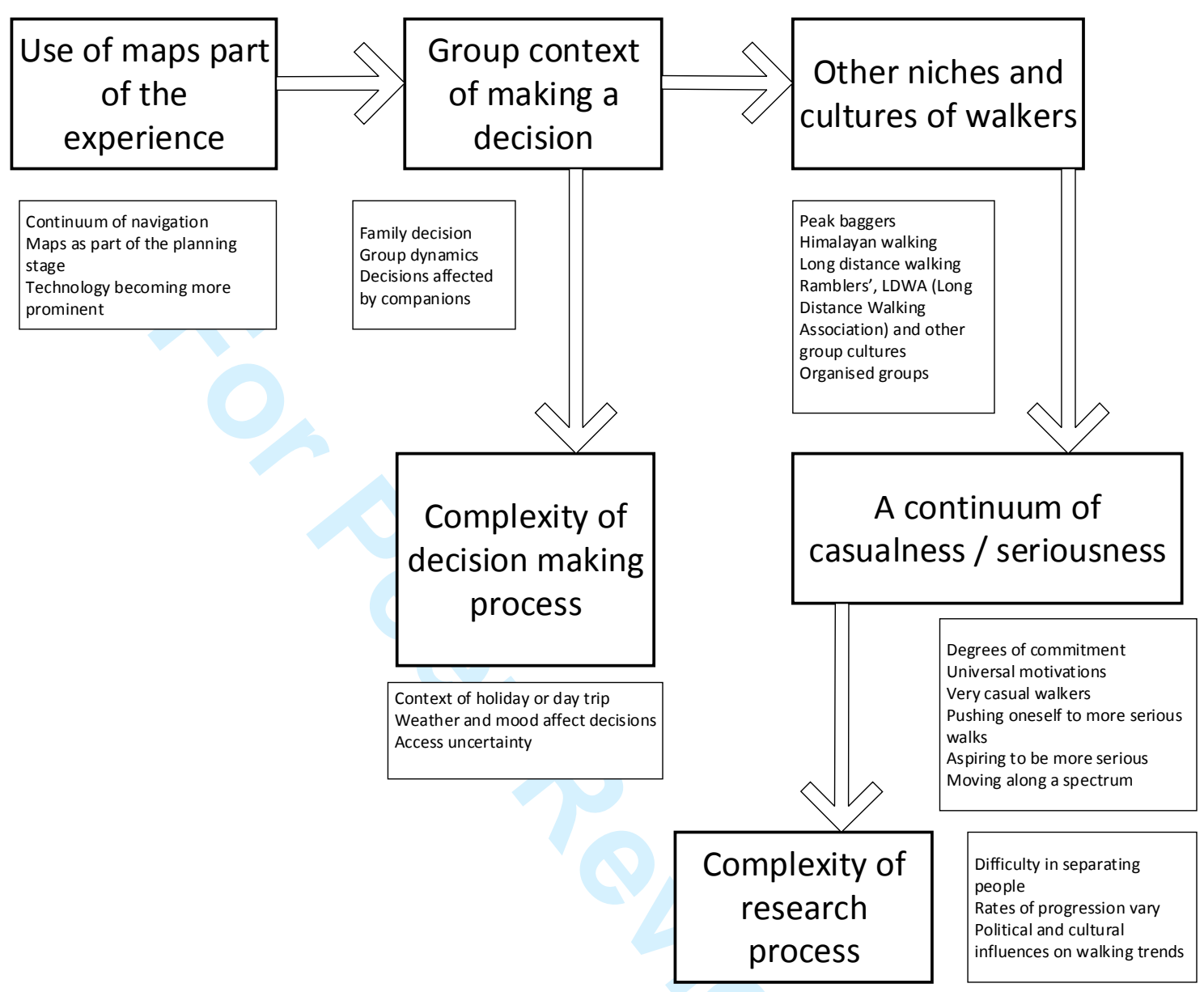


Mood and energy affect route choice Group dynamics

Life situation

Walkers' need for flexibility

Cultural influences

\section{Problem of generalisation}

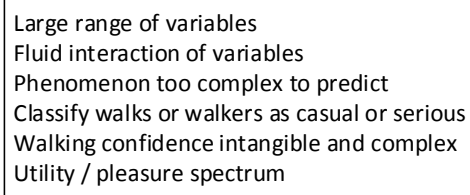

